\section{Bacteria necessary to produce experimental autoimmune myasthenia gravis in acetylcholine receptor-immunised rabbits?}

WE have ${ }^{1-3}$ described previously a paralytic disease observed in rabbits immunised with small doses, in Freund's complete adjuvant, of nicotinic cholinergic receptor protein (nAChR) isolated from the electric organ of Torpedo marmorata. Decremental muscle response after nerve stimulation and positive effects of anticholinesterase administration, decrease in miniature endplate potential amplitude and increased curare sensitivity were similar to findings in patients suffering from myasthenia gravis. Nicotinic AChR antibody titres above 2-3 $\mathrm{mg} \mathrm{ml}^{-1}$ have been found, the observed muscle decrement increasing with increasing antibody titre. Occasionally, variations in electromyographic activity were observed, suggesting denervation. Morphological analysis ${ }^{3,4}$ showed severe destruction of postsynaptic motor endplate areas and reduction of toxin-binding sites, followed by changes at the presynaptic side. A second stage of the disease was characterised by high sensitivity to nAChR injections and by the presence of motor endplates lacking secondary postsynaptic foldings. Our work and that of others (for review see ref. 5) suggests that an immune response to $n A C h R$ seems to be involved in the aetiology of experimental autoimmune myasthenia gravis (EAM) just as is suggested for human myasthenia gravis. The role of a humoral and/or cellular immune response and that of the thymus are under discussion ${ }^{5,6}$. The decremental response to repetitive nerve stimulation may be caused directly and/or indirectly by $\mathrm{nAChR}$ antibodies, whereas defects in electromyographic activity such as high frequency discharges and fibrillation action potentials which we have observed may have been caused by other, accompanying mechanisms. This report deals with the role of bacteria in EAM and with the relationship of the antibody titre to the electrophysiological findings.

A sterile-filtered receptor solution produced a low antibody titre, and no decremental response on repetitive stimulation or response to Tensilon was observed. The nAChR used previously ${ }^{1-3}$ in immunisation which always resulted in animals with EAM was obtained after solubilisation with phosphate buffer containing $1 \%$ Triton $\mathrm{X}-100$ and purification by affinity and ion-exchange chromatography. Sodium azide $(0.02 \%)$ was added to the purified receptor to prevent further growth of bacteria. About 30 rabbits were immunised with such preparations, all of which showed typical symptoms of EAM.

We have introduced a sterile filtration step (Millipore filters, pore size $0.22 \mu \mathrm{m}$ ) after Triton $\mathrm{X}-100$ solubilisation to reduce bacteria present from $4,000-12,000$ to $30 \mathrm{ml}^{-1}$.

Table 1 Relationship between $\mathrm{nAChR}$ antibody titre and decremental muscle response after repetitive stimulation of peroneal nerve

$\begin{array}{ccc}\begin{array}{c}\text { Rabbit } \\ \text { no. }\end{array} & \begin{array}{c}\text { Antibody titre } \\ \left(\mathrm{mg} \mathrm{m}^{-1}\right)\end{array} & \begin{array}{c}\text { Decrement } \\ (\%)\end{array} \\ 1 & 2.9 & 56 \\ 2 & 4.9 & 25 \\ 3 & 6.7 & 62 \\ 4 & 3.0 & 37 \\ 5 & 3.4 & 40 \\ 6 & 0.7 & 5 \\ 7 & 1.2 & 8 \\ 8 & 0.7 & 6 \\ 9 & 0.7 & 6 \\ 10 & 0.5 & 7\end{array}$

Antibody titres and decrement in rabbits immunised with a non-sterile (1-5) and a sterile (6-10) receptor preparation.
The receptor obtained had chemical and physical properties similar to those of material obtained previously, except for a considerably lower antigenicity, as expressed in obtained antibody titre in otherwise identical conditions. Rabbits immunised with a 'sterile' receptor show greater variability in the onset time for the disease, but the clinical picture observed is close to those animals observed previously. The electrophysiological investigations revealed only a very small decrement, about $5-10 \%$, which could not be responsible for the severe visible symptoms in the examined rabbits. An analysis of the receptor antibody titres (rocket immunoelectrophoresis) showed that these are rather low, below $1.2 \mathrm{mg} \mathrm{ml}^{-1}$. A return to receptor purification without sterile filtration resulted in rabbits with high antibody titres and greater decrement. Results from ten rabbits are summarised in Table 1.

We conclude that so called 'EAM rabbits' may suffer from at least two different kinds of defects: one at the neuromuscular junction, which may be of the kind observed in myasthenia gravis (this defect seems to be clearly correlated with the titre of circulating antibody to $\mathrm{nAChR}$ ); and one, responsible for the severe symptoms visible in rabbits immunised with receptor isolated after sterile filtration, which seems to involve denervation rather than neuromuscular deficiency, revealed in the electromyographic investigation as high frequency discharges and fibrillation action potentials". These effects were observed also at low $\mathrm{nAChR}$ antibody titres.

We have found therefore that besides 'myasthenic symptoms' EAM rabbits seem to have another type of weakness, not correlated with high antibody titre. We may be dealing with a potentiation of $\mathrm{NAChR}$ antigenicity, but a specific effect of a bacteria-for example, due to binding to and/or transformation of nAChR may well be the explanation. It is also possible that the filtration step removes non-bacterial material-for example, aggregated proteins. We have, however, not noticed a lower receptor yield in our final preparations.

\section{Edith Heilbronn} Christer Mattsson

Section of Biochemistry,

National Defence Research Institute,

S-17204 Sundbyberg 4, Sweden

Eric Stål.berg

Department of Clinical Neurophysiology,

Academic Hospital,

S-750 14 Uppsala, Sweden

Received April 9; accepted June 29, 1976

1 Heilbronn, E., and Mattsson, C.. I. Neurochem., 22, 315 (1974)

Heilbronn, E., Mattsson, C., Stălberg, E., and Hilton-Brown, P., J. neur. Sci., 24, 59 (1975)

Heilbronn, E., et al., Ann. N.Y. Acad. Sci., 274, 337 (1976).

4 Thornell, L.-E., Sjöström, M., Mattsson, C., and Heilbronn, E., J. neur. Sci.

(in the press).
Heilbronn, E., in Motor Innervation of Muscle (edit. by Thesleff, S.) (Academic, New York and London, in the press). Lennon, V. A., Lindstrom, J. D., and Seybold, M. E., Ann. N.Y. Acad. Sci.,
274 (1976).

\section{Cyclic AMP and cyclic GMP may play opposing roles in influencing force of contraction in mammalian myocardium}

CrCLIC AMP and cyclic GMP have been suggested to play opposing regulatory roles in several biological systems ${ }^{1}$. Supporting evidence for the yin yang hypothesis of opposing biological regulation has been obtained in sympathetic ganglia ${ }^{2,3}$ and pyramidal neurones in the rat cerebral cortex ${ }^{4}$. In the mammalian heart, the role of cyclic AMP in mediating the positive inotropic response to catecholamines was advanced by the observation that the inotropic effect was preceded by an increase 